\title{
XLI. Observations on a remarkable exudation of ice from the stems of vegetables, and on a singular protrusion of icy columns from certain kinds of earth during frosty weather
}

John LeConte M.D.

To cite this article: John LeConte M.D. (1850) XLI. Observations on a remarkable exudation of ice from the stems of vegetables, and on a singular protrusion of icy columns from certain kinds of earth during frosty weather, Philosophical Magazine Series 3, 36:244, 329-342, DOI: 10.1080/14786445008646494

To link to this article: http://dx.doi.org/10.1080/14786445008646494

\section{曲 Published online: 30 Apr 2009.}

Submit your article to this journal ए

\section{щll Article views: 3}

Q View related articles ¿ 
THE

\section{LONDON, EDINBURGH AND DUBLIN \\ PHILOSOPHICAL MAGAZINE}

A N D

JOURNAL OF SCIENCE.

[THIRD SERIES.]

$M A Y 1850$

XLI. Observations on a remarkable Exudation of Ice from the Stems of Vegetables, and on a singular Protrusion of Icy Columns from certain kinds of Earth during frosty weather. $B y$ John LeConte, M.D., Professor of Natural Philosophy and Chemistry in the University of Georgia*.

T $T$ is certainly a remarkable circumstance, that phænomena 1 so striking as those forming the subject of this paper have received so little attention from philosophers; and it is perhaps still more singular, that hitherto no attempts have been made at their explanation. Stephen Elliott, in his Sketch of the Botany of South Carolina and Georgia, published in 1824, notices a remarkable protrusion of crystalline fibres of ice from the stems of the Conyza bifrons (vol. ii. p. 322). Sir John F. W. Herschel published a short notice of a similar exudation of icy fringes occurring around thistle-stalks and stumps of heliotropes, in the London and Edinburgh Philosophical Magazine for February 1833,p. 110 (3rd series, vol. ii. p. 110)†. Professor S. P. Rigaud of Oxford notices the occurrence of an analogous phænomenon on a recently built stone wall, in the succeeding Number of the same Journal (3rd series, vol. ii. p. 190. 1833). As far as my researches extend, the abovementioned notices-all of them very brief and imperfectembrace all the observations hitherto made on these remarkable phænomena. Even the natural speculative tendency has been

* Communicated by the Author, having been read before the American Association for the Advancement of Science, at their extra meeting at Charleston, South Carolina, March 12,1850.

+ James D. Dana appears to have noticed the same phænomenon. He says, "On the cool mornings of spring or autumn in this climate, twigs of plants are occasionally found encircled by fibrous icy curls, which are attached vertically to the stem.' (Vide Manual of Mineralogy, 2nd Ed. p. 46. New Haven and Philadelphia, 1849.)

Phil. Mag. S. 3. Vol. 36. No. 244. May 1850. 
held in check by the extreme paucity of facts and observations, so that no explanation of them has been advanced.

For many years my attention has been drawn to the remarkable deposition of ice around the stalks of certain plants, as well as to analogous phænomena exhibited by certain kinds of soil. During a visit to the sea-coast of Georgia in the months of November and December 1848, I had a very favourable opportunity of studying the phrnomenon as exhibited in vegetables. The plants in which $I$ have observed it are two species of the genus Pluchea of DeCandolle, or Conyza of the older botanists, viz. Pluchea bifrons and $P$. camphorata. It is more common and conspicuous in the former species than the latter. Both of these plants grow abundantly in wet soils, around ponds and along the road-side ditches in the low country of Carolina and Georgia. The root is perennial, but the stem is annual and herbaceous.

The exudations of ice are most abundant and striking during the first clear frosty weather in November and December. At this period the earth is warm; and the serenity of the atmosphere is so favourable to radiation, that there is a remarkable difference between the temperature of the day and night. When the temperature sinks towards daylight to about $30^{\circ}$ or $28^{\circ}$ of Fahrenheit, or even lower, the surface of the ground is totally devoid of the slightest incrusting film of frozen earth, while hoar-frost is deposited in such profusion on all dead vegetable matter as to resemble a sligbt fall of snow. Under such circumstances, the traveller who passes along the level roads of this region soon after sunrise cannot fail to be struck with the remarkable accumulations of voluminous friable masses of semi-pellucid ice around the footstalks of the Pluckea which giow along the road-side ditches. At a distance they present an appeszance resembling locks of cotton-wool, varying from four to five inches in diameter, placed around the roots of the plants; and when numerous, the effect is striking and beautiful.

In relation to the exudation of ice from the stems of vegetables, the description and delineation given by Sir John Herschel are so clear and faithful, and accord so exactly with the results of my own observations, that I prefer using the language of that justly distinguished philosopher whenever it suits my purpose. The engraving which accompanies his paper represents the appearances presented very accurately*. My observations appear to establish the following facts in relation to this phænomenon:-

* The reader is requested to refer to the engraving given by Sir John Herschel in the Philosophical Magazine for February 1833. 
1. The depositions of ice are entirely confined to the immediate neighbourhood of the roots of the plants, the upper parts of the tall unbroken stalks being quite free from them. They frequently commence two or three inches from the ground, and extend from three to four inches along the axis of the stem. It is proper to state, that at this season the stalks are dead and quite dry to within about six inches of the earth, below which they are generally green and succulent. The plant has a large and porous pith, which is always saturated with moisture as high as six or seven inches from the base of the stem.

2. The ice emanates in a kind of riband- or frill-shaped wavy friable semi-pellucid excrescence, " as if protruded in a soft state from the stem, from longitudinal fissures in its sides." As Sir John Herschel remarks, "The structure of the ribands is fibrous, like that of the fibrous variety of gypsum, presenting a glossy silky surface, the direction of the fibres being at right angles to the stem, or horizontal." According to my observations, the number of ribands vary from 1 to 5. All of them issue from the stem in vertical or longitudinal lines, which are not always symmetrically disposed around the axis. Judging from the engraving given by Sir John Herschel, the Pluchea exhibits the phænomenon much more conspicuously and beautifully than the stumps of heliotropes observed by him. I have frequently observed the icy excrescences to exceed five inches in length; and when thus elongated, they are usually curled; often so much so, as to bring the remote extremity of the frill nearly in contact with its line of attachment to the stalk.

3. "Although," as Sir John Herschel correctly observes, " the icy sheets appeared to have been protruded from the interior of the stem, yet on examination they were found to terminate sharply at its surface, adhering to it so lightly as to render it impossible to handle a specimen without detaching them, and in no instance connected with any formation of ice within; on the contrary, the majority of the stems were sound and solid, and many of them still green when cut. The point of attachment of the ice was, however, always on the surface of the wood, beneath the outer bark or epidermis, which the frozen sheets had in every instance stripped off and forced out to a distance. Where the fringes were large and welldeveloped, the bark had quite fallen off; but in those cases where it adhered more strongly, it seemed to have prevented their free expansion; and in such instances the stem presented the singular appearance of a thick massive coating of ice interposed between the wood and its integument, which was $\mathrm{Z} 2$ 
swollen and rifted." To the foregoing very accurate description I have only to add, that, according to my observations on the Pluchea, when the frost is quite severe, the icy sheets were often "connected with the formation of ice within," in fact, were continuous with the frozen pith ; but under such circumstances the wood was always rifted longitudinally, and the process of protrusion seemed to have been completely checked at the part of the stem in which this took place. Indeed, the phænomenon was seldom exhibited in its nost perfect and beautiful form when the wood was split. It is obvious, therefore, that in these instances the frigorific action was too intense to permit the phænomenon to be developed in a normal manner.

4. The phænomenon took place in the same plant during several consecutive nights; and when the wood was not rifted, frequently from the same portion of the stalk. When the wood was split, however, the deposition of ice occurred lower down the stem, at a part which was unaffected by the frost of the previous night. The stalks thus became completely rifted by a succession of severe nights, from the height of six or seven inches down to the ground. This is unquestionably one of the reasons why these exudations of ice are seldom observed after the middle of winter, for the stalks are usually destroyed before this period.

5. The stems which had been cut off within three or four inches of the earth exhibited the phænomenon as conspicuously as those which were left untonched. The icy sheets never issued from the cut surface, but always from longitudinal lines commencing somewhat below it and extending towards the root. Plants which were torn up and transplanted in a box of moist earth in a flower garden exhibited the same phænomenon, although much less strikingly than when left in situ.

"The appearances above described," to use the language of Sir John Herschel, "are quite at variance with any idea of the deposition of these icy fringes from the store of aqueous vapour in the general atmosphere, in the manner of hoarfrost; and the only quarter to which we can look for their origin is in the plant itself, or in the comparatively warm earth beneath, to whose exhalations the decaying stems may form a kind of chimney." The additional facts which my observations establish,- particularly in relation to the recurrence of the phænomenon on the same portion of the stalk during several successive frosts, even after it had been cut off, -appear to be irreconcileable with the idea that the physiological functions of the plant have any share in the production of it. We must therefore look to the moist earth for the large 
supply of water necessary for the development of these vo.uminous masses of ice. But by what force and through what agency is it elevated and protruded?

Impressed with the idea that the phænomenon is purely physical, having no connexion with the vitality of the stem, it seemed reasonable that the remarkable exudation of icy co. lumns from certain kinds of earth, which long attracted my attention, might be referred to a similar cause. Considerations of this character induced me to study the latter phanomenon more carefully. During the winters of 1848-49 and 1849-50, abundant opportunities occurred of examining the phænomenon under the most diversified circumstances, the soil in this neighbourhood being peculiarly adapted to its development.

The following facts seem to be established by my observations:-

1. The phænomenon occurs most strikingly when a warm rainy period terminates in clear freezing weather, with the wind from the west or north-west. It is more or less distinctly developed at all temperatures below $30^{\circ}$ Fahrenheit. When, however, the thermometer was as high as this at sunrise, it was exhibited only in situations most favourable to radiation. It frequently appears during several consecutive nights after a rain; but usually, when the temperature remains nearly constant, with decreasing conspicuousness. This obviously arises from the diminution of moisture: in situations which are persistently wet, it is always dereloped in proportion to the depression of temperature.

2. It takes place in soils that are rather firm, but not very compact. For example, the phænomenon is beautifully exhibited along the sides of the water-worn ravines which furrow the declivities of the firm red clay hills of this primitive region, as well as along the cuts or ditches by the road-side. This clay seems to be formed by the decomposition, in situ, of hornblendic gneiss and mica-schist. This soil presents the same phænomenon when thrown up and lying on the surface, provided it is not trodden down and rendered too compact. For this reason it never appears on the well-beaten high roads, although it is seen abundantly along their margins. The influence of compactness of soil is strikingly illustrated by the fact, that the protrusion of the icy columns will frequently occur around the margins and along the middle cleft of a track of a cloven-footed animal, while none were found on the portions where the clay had undergone compression. The clods found at the bottom of the ravines and along the margins of the brooks generally afford beautiful manifestations of the 
phænomenon, under proper circumstances. It is seldom, if ever, observed in rich, mellow, alluvial soils, abounding in vegetable matter.

3. The general appearance of the phænomenon is that of a vast number of filaments of ice, forming in their aggregation fibrous columns resembling bundles of spun glass, emanating at right angles to the surface, as if protruded in a semi-fluid state from an infinitude of capillary tubes in the ground. The structure of the columns is distinctly fibrous, presenting a fine silky, wavy, silvery surface, analogous to that of the fibrous variety of gypsum. They exhibit various degrees of diaphaneity, apparently depending on the purity of the water as well as on the state of aggregation of the icy filaments; being in some situations almost perfectly transparent, and in others scarcely semi-pellucid. Sometimes the fibres composing the columns are readily separable; at other times they are, as it were, fused together. When examined by transmitted light, transverse strice are observed to cross the filaments at intervals varying from $\frac{1}{10}$ th to $\frac{1}{30}$ th of an inch. A thin stratum or crust of loose frozen earth is frequently detached and elevated on the summits of the columns, often forming a continuous roof-like covering to the soil beneath, extending over many square yards; at other times appearing in separate and isolated flat caps of variable size. The columns are not always uniformly distributed over the surface of the ground, but frequently exhibit considerable intervals of unfrozen soil between them. When the exudation takes place around the margins of a circumscribed depression containing water, like that left by the foot of a horse, it appears to draw up the water from the cavity, leaving an interior grotto lined with fantastic groups of icicles. "The icy columns vary in length from one to three, four, or even five inches, according to the favourableness of the situation and the intensity of the cold. 'They vary in size from mere threads to prismatic bundles of onefourth of an inch in diameter. When very long they frequently fall over by their gravity, presenting a beautiful appearance when viewed in masses. The effect produced by walking over a surface on which the phænomenon is welldeveloped is very striking. The superior crust of frozen earth and its supporting icy columns give way under the foot, which thereby sinks several inches below the apparent surface at every step. When the phænomenon occurs along the precipitous sides of the ravines and road-side cuts, the earth which has been elevated falls down to the bottom of the inclined plane as soon as the sun takes effect, leaving a fresh surface of soil exposed to the action of the next frost; and as this ex- 
foliation continues from night to night when the weather is sufficiently cold, while all the earthy matter which is thus thrown down is carried off by the first considerable fall of rain, it is sufficiently obvious that it is a powerful agent of disintegration. When the weather is not severe, it is only exhibited in situations most favourable to the production of cold. The presence of a twig or a straw on the surface of the clay will, under these circumstances, determine the place of development of the phænomenon; and a twig will thereby be elevated above the general surface, supported by an elegant pectinated arrangement of icy columns.

4. On examination the icy columns were found to terminate sharply at the surface of the clay, adhering so lightly as to be detached by a mere touch of the finger, and scarcely ever connected with any formation of ice below, -in fact, never, under the circumstances most favourable to the development of the phænomenon. On the contrary, in the majority of cases, the soil from which they protruded roas not frozen in the slightest degree, even during our severest weather, and when the earth in other situations was completely incrusted. This point was carefully examined early in the morning on the 11 th of January 1849, when the thermometer was at $14^{\circ}$ of Fahrenheit at sunrise; again on the 17 th of February, when it was at $12^{\circ}$; and again on the 19th of the same month, when it stood as low as $5^{\circ},-\mathrm{n}$ most extraordinary degree of cold for this latitude $\left(34^{\circ} \mathrm{N}\right.$. lat. $)$. These observations were carefully repeated on the mornings of the 4th, $5 \mathrm{th}$, $6 \mathrm{th}$, and 7 th of $\mathrm{Fe}-$ bruary 1850 , when the temperature was respectively $16^{\circ}, 14^{\circ}$, $18^{\circ}$, and $23^{\circ}$ of Fahrenheit's scale at sunrise. On none of these occasions was the ground, where the icy columns were developed in profusion, frozen in the slightest degree. The afternoon of February 4, 1850, afforded me the rare opportunity of observing the phænomenon in the very act of development. It took place on an eastern exposure at $5 \frac{1}{2}$ P.M., when the temperature was $28^{\circ} \mathrm{F}$. As the day was very cold, the icy columns of the previous night, which were about three inches in length, had been only partially melted, in this protected situation, by the influence of the mid-day sun. At the time the observation was made, these columns were found to be elevated about one inch by the recently protruded ice. The line of demarcation between the old and new ice-formation was perfectly distinct, the lower portions of the former having been remarkably attenuated by the process of liquefaction during the heat of the day. In this case it was obvious that the evolution of the phænomenon during the previous night and morning had been temporarily checked by the solar 
heat, but was resumed as soon as that influence was withdrawn. The state of the soil was carefully examined; for it seemed to be almost certain, that the process of formation must have been going on under the eye at the time the observations were made. The subjacent clay was found to be moist and unfrozen, the icy columns separated from it with the slightest touch, and were not connected with any formation of ice beluw. As already intimated, in less favourable situations, when the frigorific action was intense, the soil on which the columns rested sometimes became incrusted with ice, after the protrusion had commenced; but this was invariably attended with a complete arrestation of the process: indeed, under such circumstances, it was obvious that there had been an imperfect development of the phæuomenon. In these cases, a stratum of frozen earth was found adhering to the bases of the columns, while continuous icy threads were observed to transpierce this crust perpendicularly, and occasionally to extend into minute apertures in the unfrozen soil beneath it. As already remarked, in more favourable situations the ground beneath was never frozen; but on cantiously removing the icy columns, the moist clay was found to present a very porous appearance, as if perforated by a multitude of holes or spiracles, corresponding in position with the bundles of thread-like ice, and which were frequently of sufficient size to be quite obvious to the unassisted eye.

Having thus described with sufficient fullness the phænomena attending the occurrence of exudations of icy fringes from the stems of plants, as well as the protrusion of colunns of ice from certain soils, we are now prepared to offer something in explanation of them, and to attempt to rise from the mass of details to the causes which have given birth to these remarkable appearances. A careful examination and collation of the two series of facts above recorded develope so many strong points of analogy, that it is almost impossible to resist the conviction, that both of the phænomena must be referred to the same cause. If we admit an identity of cause in the two cases, it is obvious that it must be purely physical; since that which relates to the production of the phænomenon on certain kinds of earth is necessarily physical. In the remarks which follow, therefore, I shall treat the question as one of physics, and shall apply them more particularly to the phænomenon exhibited by the soil: their application to the case of vegetables will be easy and obvious.

1. It is very clear that we cannot look to the store of vapour in the general atmosphere for the origin of the icy columns. For not only are the appearances above described at 
variance with the idea of the phæromenon being a modification of hoar-frost, but the amount of water congealed at the surface during a single night is vastly too great to have come from this source. Moreover, the phænomenon occurs very conspicuously during our most violent and dry northwest winds ; circumstances under which it would be impossible for any condensation of atmospheric vapour to take place. It is well known to meteorologists, that a rapid agitation of the lower strata of the atmosphere totally subverts the condition which is most essential to the deposition of dew, namely, that the surface must be colder than the superincumbent air.

2. It cannot be occasioned by the cold contracting a superficial stratum of earth, and thus forcing up the moisture which freezes at the surface, because this cause is utterly inadequate to furnish the large supply of fluid which is required for the production of columns of ice from three to five inches in length. The fact that isolated clods lying in moist situations frequently exhibit a protruded investment of icy columns quite equal in volume to the mass of earth from which they issued, is obviously and palpably at variance with this idea. The phænomenon observed on the stems of plants is likewise manifestly inconsistent with this notion.

3. It cannot be owing to the exhalation of aqueous vapour from the comparatively warm earth beneath through spiracles, undergoing condensation and congelation at the surface, and thus protruding the columns; for the amount of evaporation from such a surface, when the temperature of the air is at 12 or 14 degrees of Fahrenheit's scale, is hopelessly inadequate to furnish the necessary amount of water. Frequently during a single night a sufficient quantity of moisture is elevated in the form of icy columns to maintain the surface in a very wet condition, even after several days' exposure to the sun.

4. Neither can the protrusion of the columns of ice be ascribed to the mere expansion of water during the act of freezing in the capillary tubes in the clay; for this supposition is opposed to the well-established fact, that they are not connected woith any formation of ice below. Besides, if we assume the specific gravity of ice to be $\cdot 92$ as compared with water at $32^{\circ} \mathrm{F}$, it follows that the amount of expansion which it undergoes during the process of congelation is about 87 parts in 1000 by volume. Granting the rigidity of the capillary tubes to be such as to admit of no transverse increment, and that the rohole amount of cubic expansion is thereby manifested in the longitudinal extension of the column, it appears, from a simple calculation, that to protrude three inches of ice the frozen column must penetrate about thirty-four inches be- 
low the surface of the soil. We have already seen that the ice does not extend below the surface when the phrenomenon is well developed; and it is well known that the degree of cold necessary for freezing water is never observed in this latitude at a greater depth than one or two inches.

5. In seeking for a cause of the elevation of the fluid, the first suggestion which presented itself to my mind was the well-known and remarkable expansion which water undergoes before congelation commences. In this we have a vera causa, of sufficient universality and acting in the right direction, to account for the phænomenon, and yet perfectly consistent with an important invariable concomitant circumstance, namely, the unfrozen condition of the clay. But a little reflection very soon convinced me that it must play a subordinate part in the production of the phænomenon. A simple calculation is sufficient to place the inadequacy of this cause in a striking point of view. According to the recent and very satisfactory experiments of Joule and Playfair, the maximum density of water is at $39^{\circ} \cdot 1$ of Fahrenheit's scale (Phil. Mag. 3rd Series, vol. $\mathrm{xxx}$. p. 41 et seq. 184.7). The very elaborate series of experiments of Prof. Hällström show that the mean expansion in volume between the point of maximum density and the freezing-point $\left(32^{\circ}\right.$ F.) is about 4.12 parts in $10,000,000$ (Thomson On Heat, \&c., p. 28. Lond. 1830). Hence it is obvious, that if, by the unyielding character of the capillary tubes, the whole of the increase of volume contributed to the elongation of the column, the length of the column of water requisite for furnishing 3 inches of ice through the operation of this cause would be about 72,815 inches, or nearly 6068 feet*. This reasoning is based upon the assumption, that the temperature of the water at the orifice of the tube is at $32^{\circ}$, while that at the other extremity of the column (viz. 6068 feet below the surface) is at $39^{\circ} \cdot 1 \mathrm{~F}$; the only supposition consistent with the absence of ice beneath. As the effects of cold penetrate but a comparatively short distance below the surface of the earth, the insufficiency of this cause is too apparent to deserve further notice.

Having thus shown the inadequacy of several presumed causes to produce the remarkable phænomena under consideration, it is of course expected that we should offer some ex-

* According to an extensive series of experiments made by M. Despretz, the mean expansion of water between the points of maximum density and freezing, is 482.6 parts in 10,000,000. (Vide Pouillet's Eléments de Physique Expérimentale et de Météorologie, 5th edition, vol. i. p. 293. Paris, 1847.) This makes the required length of column equal to about 62,163 inches, or 5180 feet. 


\section{from the Stems of Vegetables.}

planation of them. Before doing so, it may be well to premise, that whatever may be thought to be the proximate cause of these phænomena, all the rules of philosophizing require us to look to the earth for the supply of fluid, and to the influence of cold for the elevating force. We have seen that the effect is invariably connected with cold, that it increases or diminishes with the intensity of the frigorific influence, and that it is proportional to the depression of temperature in all cases of unimpeded action. The whole difficulty lies, therefore, in ascertaining the modus operandi of this cause.

After considerable reflection, we venture to offer the following as the most probable explanation of the phænomenon. Let us suppose a portion of tolerably compact porous and warn earth, saturated with moisture, to be exposed to the influence of a cold-producing cause. The soil being an indifferent conductor of heat, only a very superficial stratum would be reduced to the freezing-point. As the resistance to lateral expansion is less at the surface than it is at a sensible depth below, the effect of the first freezing would be to render the apices of the capillary tubes or pores conical or pyramidal. The sudden congelation of the water filling the conical capillaries in the superior stratum would produce a rapid and forcible expansion, which, being resisted by the unyielding walls of the cone, would not only protrude, but project or detach and throw out the thread-like columns of ice in the direction of least resistance, or perpendicular to the surface. This would leave the summits of the tubes partially empty, - a condition essential to the development of capillary force. Under these circumstances, capillary attraction would draw up warm water from beneath, which, undergoing congelation, would in like manner elevate the column of ice still higher; and thus the process would go on as long as the cold continued to operate on unobstructed capillaries supplied with sufficient water from below. It will be remarked, that this explanation makes the whole process of protrusion to take place in a stratum of earth of almost inappreciable thickness. It also presumes that the protruding force acts paroxysmally. Does not the wavy striated structure of the icy columns clearly indicate that the freezing process is intermittent? It is obvious that the unfrozen state of the soil is maintained through the operation of two causes; to wit, the unceasing supply of warm water from below, and the large amount of latent heat evolved during the continued process of congelation. These two causes appear to be fully adequate to explain this remarkable fact.

The foregoing view explains why the phænomenon does not take place on hard-beaten earth and on very loose soils; for, 
in the one case, the compactness of the superficial stratum not only diminishes the porosity, but renders the resistance to lateral expansion greater at the surface than it is below, and consequently interferes with the protrusion of the column of ice in the right direction; while in the other case, the openness of the soil prevents the formation of tubes possessing unyielding sides, a condition which is equally essential to the process. When the intensity of the cold is sufficiently great to freeze the soil, the process is arrested, because the capillary tubes are closed, and a resistance opposed to further protrusion. The porous appearance presented by the subjacent clay when the icy columus are removed is doubtless referable to the enlargement of the orifices of the minute capillaries, caused by the sudden expansion of the successive portions of fluid as they were frozen at the surface.

If the above is the true explanation of the phænomenon, we should expect, from à priori considerations, that in higher latitudes, where the cold is more intense and persistent, the conditions of its manifestation would exist only during the early part of winter, before the ground became deeply and permanently frozen; or else only in certain favourable situations, - as in the neighbourhood of warm springs, and perhaps along the margins of unfrozen streams, - where local causes preserved the soil in a proper condition. Are not facts in accordance with this view?

The foregoing explanation appears to afford a satisfactory interpretation of a very remarkable experiment recorded by Sir John Leslie, which is so nearly the counterpart of what takes place in nature, that we cannot forbear citing it on this occasion. He says, in treating of artificial congelation, "When very feeble powers of refrigeration are employed, a most singular and beautiful appearance is, in course of time, slowly produced. If a pan of porous earthenware, from four to six inches wide, be filled to the utmost with common water till it rise above the lips, and planted above a dish of ten or twelve inches diameter, containing a body of sulphuric acid, and then a broad round receiver placed over it; on reducing the included air to some limit between the twentieth and the fifth part of its usual density, according to the coldness of the apartment, the liquid mass will in the space of an hour or two become entwined with icy shoots, which gradually enlarge and acquire more solidity, but always leave the fabric loose and untrozen below. The icy crust which covers the rim, now receiving continual accessions from beneath, rises perpendicularly by insensible degrees. From each point on the rough surface of the vessel, filaments of ice, like bundles of spun- 
glass, are protruded, fed by the humidity conveyed through its substance, and forming in their aggregation a fine silvery surface, analogous to that of fibrous gypsum or satin spar." (Supplement to Encyclopcedia Britannica, vol. iii. art. Cold, p. 258.) The same elevating cause must have been in operation during the progress of this experiment, which produces the protrusion of icy columns from the earth *.

The phænomenon manifested on certain plants is every way analogous to that relating to the protrusion of ice from certain kinds of soil, and admits of the same explanation. The porous pith furnishes a constant supply of warm water from the earth, while the wedge-shaped medullary rays secure the mechanical conditions necessary for the development of a projectile force in the proper direction. In proof of this it may be remarked, that the medullary rays are very conspicuous in the Pluchea; and when the stalk is split by the freezing of the water within, the fissure is observed to follow their course. The development of the phænomenon is arrested when the pith becomes frozen, for the obvious reason that the consequent splitting of the stem destroys the arrangement of resisting tubes. For a like reason it is exhibited lower down the stalk when it becomes rifted; for the conditions essential to its production are there found. When the cold-producing cause is not too intense, the stalk is not frozen, for the same reason that the ground remains unfrozen under similar circumstances. The reason why the phænomenon is manifested only in certain kinds of plants, probably arises from several peculiarities in their physical condition. They must be porous to furnish an abundant supply of fluid; they must be herbaceous and annual to secure medullary rays of sufficient size and openness; and it is probable that all vital action must have ceased, in order that the fluid

* Since writing the above, my attention has been called to analogous phænomena developed during the crystallization of certain salts.

If the smaller portions of the soft and spongy roots of our conimon cypress (Cupressus disticha, Mich.) be thoroughly soaked in a solution of nitrate of potash, and exposed to the drying influence of the air at ordinary temperatures, the whole surface will in process of time be covered with a most delicate investment of hair-like crystalline fibres. They are always observed to emanate at right angles to the convex surface of the root in the form of radial prolongations, and often extend out from the wood to a distance equal to, or exceeding its semi-diameter. When brushed off by the finger, a fresh crop speedily appears. A similar exudation of crystalline filaments of sulphate of zinc is frequently observed on the surface of the porous earthenware cups used in Grove's battery, when they are not carefully washed. It is obvious that these phænomena are identical in their origin with the protrusion of the columns of ice from the earth, excepting that in the latter case the influence of cold is essential to the process of crystallization. 
which is elevated from the soil may be unmixed with the proper juices of the plants, a mixture which would interfere with congelation.

We conclude these observations with a few remarks on the teleological bearing of the phænomenon which we have been considering. The laws of the effect of temperature on water are so remarkable in their adaptation to the beneficial course of things at the earth's surface, that they have never failed to impress the student of Nature with the most profound admiration of the wisdom and goodness of the Great Designer. Among these, the infinite importance of the latency of heat in the œconomy of nature is one of the most striking. In the phænomenon which we have had under consideration in relation to the protrusion of icy columns from the earth, we recognize an extension of this law, the importance of which it is scarcely possible for us to over-estimate. By an admirable combination of the laws of expansion and capillary attraction, a vast amount of water is brought to the surface of the soil, and there disengages its latent heat in the act of congelation, thereby softening the rigours of winter, and preserving the roots or bulbs beneath the surface of the ground from the destructive effects of cold. Even on those portions of the soil where the phrnomenon does not manifest itself in the protrusion of columns of ice, it is extremely probable that the same law operates to a more limited extent. This seems to be proved by a fact, which must have come under the observation of every one; namely, that the amount of moisture found at the surface of the ground after a thaw is vastly greater than was present before congelation took place. This is the case, under circumstances which are incompatible with the idea of the deposition of dew; the water must therefore have been elevated from the depths of the earth. The philosopher who loves to dwell on causes and effects, and to trace the deep processes of thought by which the great purposes of nature have been revealed, both in the heavens above and in the physical condition of the earth on which he treads, will be gratified to discover in every portion of the universe those prospective arrangements, compensations, minute adaptations, and comprehensive inter-dependencies, which characterize the works of an omníscient Architect.

Athens, Georgia, Feb. 25, 1850. 